\title{
Propuestas sobre el Arte y la Educación
}

\author{
Alejandro González*
}

\section{Resumen}

El presente texto plantea, desde una perspectiva Vigotskyana, los posibles fundamentos de las extraordinarias mejoras que se obtienen al introducir la libre discusión del arte en el proceso educativo. De cómo el modo metafórico de procesar la información, se encuentra en las estrategias del pensamiento individual que permiten generar avances en la promoción y adquisición del pensamiento científico.

Palabras claves: Aprendizaje. Arte. Metáfora.

\footnotetext{
*Universidad de Buenos Aires, Argentina. Subdirector del Ateneo Vigotskyano de la República Argentina. Docente de la Escuela de Psicología Cientifica del SARCU (Sociedad Argentina de Relaciones Culturales con la Unión Sovietica) entre los años 1979 a 1989.
} 


\section{Presentación}

Mi intervención, a diferencia de la mayor parte de los disertantes, va a tener primordialmente un enfoque de orden técnico. Dicho enfoque se sustenta en las postulaciones de Vigotsky, a partir de las cuales se intentara abrir una nueva luz a ciertos aspectos atinentes a la relación entre el arte y la educación.

No obstante, me siento en la obligación de realizar una aclaración que considero pertinente. Mi intervención, hoy traducida en este escrito, habrá de dar por sentados ciertos supuestos comunes. Ya que en más de una oportunidad, los marxistas nos sentimos obligados a retomar los supuestos que fundamentan nuestras postulaciones (creo que esto se debe básicamente, a la novedad y la vigencia que conllevan, aún al día de hoy, los postulados del marxismo) extendiendo casi geométricamente la longitud de nuestros escritos, longitud que se transforma en lejanía respecto de los posibles lectores. Ya que he aprendido que existe una proporcionalidad inversa entre la extensión de un texto y la cantidad de lectores.

\section{Constitución de la subjetividad}

Con el advenimiento de la modernidad es decir en los inicios del capitalismo, se modifican sustancialmente las formas de producción de subjetividades.

El auge del individualismo, de la mano de varios factores, siendo el primordial aquel que señalara Marx $(1973,1983)$ en relación a la necesidad de mano de obra libre. Por lo tanto, de obreros y productores libres. Así como en un principio, la necesidad de generación de ciudadanos, en orden a las nuevas formas de estructuración social. Ciudadanos que debían estar dotados de capacidades intelectuales que les permitirán incorporarse a un sistema productivo mucho más complejo que el precedente.

No obstante, con el avance de los tiempos éstos ciudadanos podrían poner en peligro, en función de un cierto espíritu crítico, las bases del sistema, fueron convirtiéndose progresivamente en consumidores, en su gran mayoría. Dicha situación los ataba aún mejor a las necesidades del propio sistema.

Pero estas individualidades nacen preñadas, por las cualidades inherentes al sistema, de un espíritu mayoritariamente competitivo. Marx denunciaba esto al decir que la expresión de la libertad por antonomasia de la revolución 
burguesa era expresada en los términos propios de la revolución francesa. Esto es, que la libertad de cada uno llega hasta donde llega la libertad de los demás. Donde los demás son el límite de mi libertad y no la condición de posibilidad de la extensión de la misma.

Es justamente, en estas condiciones en las que se inserta la institución educativa, la que, por tanto, es planteada como una generadora de individuos competitivos entre sí. La máquina productora de individualidades genera competidores-consumidores.

Sin embargo, esta escuela, además de transmitir conocimientos concretos, ejercita a los estudiantes en el uso de herramientas e instrumentos del pensamiento, generando distintos niveles de maestría en su utilización. Dicha ejercitación la realiza la escuela adaptándose a las reglas que el propio sistema induce. Esto es, poniendo al sujeto (nunca mejor usado este término) en un lugar preponderantemente pasivo. Básicamente un mero aplicador de técnicas diseñadas por otros. Gracias a este modelo el sistema a través de la institución escolar se permite transmitir los contenidos con los que busca formatear el pensamiento del estudiante.

Plantear la educación desde el marxismo, es algo absolutamente diferente. En principio se trata de producir condiciones de subjetivación que permitan el alumbramiento de individuos con plenas capacidades de discernimiento y pensamiento autónomo. Rompiendo con las relaciones de hegemonía y de dominación que se establecen en la relación áulica tradicional.

En principio, el planteo ya no será producir sujetos competitivos, sino por el contrario, individuos cooperativos. Y para ello, debemos replantear los fundamentos mismos de la educación. Adaptarla a las condiciones en las condiciones en que los individuos puedan, a la vez que interiorizar los instrumentos del pensamiento, realizar con ellos una labor que permita a su mundo interior - en su particular capacidad de recambiar elementos constitutivos - expresarse innovadoramente, produciendo una dialéctica que contribuye a enriquecer la vida cultural del entorno objetivando creativamente su mundo subjetivo.

Al decir de Vigotsky (1972) se trata de individualizar lo general y de generalizar lo individual. De esta forma, el sujeto rompe con los límites de su propia individualidad sumándose al torrente del flujo general del pensamiento humano aportando la riqueza de su propia individualidad. Transformando al 
individuo competitivo en un individuo cooperativo.

Es justamente, en este aspecto en el que se va a centrar mi intervención.

\section{Transmisión precisa o transmisión creativa}

El planteo de la trasmisión de instrumentos de conocimiento y de saberes catalogados, supone un cierto grado de precisión tanto en la adquisición como en el uso de tales instrumentos y saberes. El saber científico, aquel en el que se centra la trasmisión educativa, se constituye en función de la exactitud de sus contenidos en oposición a los conocimientos espontáneos que pueden adquirirse por fuera de la institución escolar. El objetivo último de la educación tradicional consiste justamente en que el nińo vaya adquiriendo progresivamente las "disciplinas" del pensamiento científico. Ello supone, por tanto, vías de ingreso más estrictas debido a los límites que exige la exactitud.

Se genera así la presunción de que las formas de acceso al pensamiento "correcto" son extremadamente limitadas, a las que el sujeto debe adecuarse y adaptarse. Forjándose desfiladeros muy angostos por los que debe transitar el pensamiento infantil, en un trayecto de adaptación extrema que suele desembocar en una especie de generalización-despersonalización de las estrategias de abordaje del conocimiento.

Sin embargo, al adentrarnos en la historia de la ciencia descubrimos que el pensamiento científico no ha avanzado justamente en el momento de su mayor adaptación a las cláusulas de precisión y exactitud. Por el contrario, a partir de los aportes de Lakoff y Johnson (1991), descubrimos que todo avance en el área de las ciencias se enraíza en formas de pensamiento que solían ser expulsadas de los territorios propios del pensar científico. Dichos investigadores han descubierto que no es únicamente la rigurosidad de la razón la que nos permite avanzar en el terreno científico. Por el contrario, han demostrado que toda nueva adquisición en las diferentes áreas de la ciencia surge como consecuencia de formas de pensar que mucho se alejan del rigor, permitiéndose deambular por caminos menos estrechos. La metáfora según estos autores es el condimento esencial del avance de la ciencia. Sin embargo esta idea que logra imponerse en la epistemología tiene un antecedente sumamente llamativo en la obra de Vigotsky (1972). Así es en el capítulo dos de La psicología del arte en el análisis de la proposición de Potebnia de considerar al arte como un conocimiento dice: 
De este modo, el mecanismo de los procesos psicológicos correspondientes a la obra de arte, empieza a esbozarse a partir de esta analogía, y además se establece que el simbolismo o la elasticidad de la palabra se iguala a su "poeticidad" y, de este modo la imagen deviene la base de la vivencia artística, y las propiedades comunes del proceso intelectual y cognoscitivo, su característica general. El nińo que contempla por vez primera un globo de cristal, lo denomina Sandía, y así explica una impresión nueva y desconocida mediante una noción anterior y conocida (la Sandía). (VIGOTSKY, 1972, p. 49-50).

La vieja noción de "Sandía" ayuda al niño a percibir la nueva adquisición (VIGOTSKY, 1972).

Esta cualidad del desplazamiento de los sentidos de un campo perceptual a otro no es propiedad exclusiva de los avances en el campo científico, ya que la encontramos en la descripción del funcionamiento de un aspecto de nuestra vida psíquica alumbrado por un autor considerado "maldito" por cierto dogmatismo proveniente del campo "marxista". En su descripción de las Formas del Funcionamiento del Inconsciente Freud (1978b) encuentra que el corrimiento del sentido entre distintas percepciones es moneda corriente y cualidad definitoria en las producciones del inconsciente. Dicho corrimiento suele producir núcleos de sentido en el que "condensan" diversas líneas de catexias (si es que aceptamos esta "metáfora" energética del inventor del psicoanálisis).

A estas dos cualidades del inconsciente, condensación y desplazamiento, suele reunírselas bajo el nombre de Proceso Primario que es acompañado de otras cualidades como la atemporalidad, la carencia del principio de contradicción lógica, imperio del principio del placer sobre el de realidad etc. Características estas que las asimilan a otras peculiaridades del funcionamiento psíquico descubiertas por el gran psicólogo ruso Vigotsky.

Para comprender mejor estas similitudes, detengámonos un poco en la descripción que hace Freud del Proceso Primario. En principio tomaremos la que hace del fenómeno de Condensación:

El trabajo de condensación del sueńo se muestra con la máxima evidencia cuando ha escogido como objetos 
palabras y nombres. Las palabras son manejadas por el sueño con la misma frecuencia que las cosas, y experimentan idénticas urdimbres que las representaciones-cosa del mundo. Cómicas y raras creaciones léxicas son el resultado de tales sueños. (FREUD, 1978a, p. 302 ).

A continuación da una serie de ejemplos de tales "Comicas y raras creaciones léxicas" los que se producen condensaciones de varios términos, creando neologismos. Maistollmütz (Mais $\{$ maíz $\}+$ toll $\{$ loco $\}+$ mannstoll \{ninfómana\} + Olmütz [ciudad de Moravia]); Autodidasker (autodidacta y Lasker unidas por preocupaciones familiares del autor). Previamente nos había advertido que:

El contenido del sueño nos es dado, por así decir, en una pictografía, cada uno de cuyos signos ha de transferirse al lenguaje de los pensamientos del sueño. Equivocaríamos manifiestamente el camino si quisiésemos leer esos signos según su valor figural en lugar de hacerlo según su referencia signante. (FREUD, 1978a, p. 285).

Es decir, que no se deben interpretar las nuevas construcciones como simples relaciones de orden figurativo, sino en relación a la Función Simbólica, precondición de acceso a la compresión cabal del lenguaje.

Para reforzar a visión de la coincidencia de los procesos descriptos por los dos grandes psicólogos, veamos estas dos citas:

Lo primero que muestra al investigador la comparación entre contenido y pensamientos del sueño es que aquí se cumplió un vasto trabajo de condensación. El sueño es escueto, pobre, lacónico, si se lo compara con la extensión y la riqueza de los pensamientos oníricos. Puesto por escrito, el sueño ocupa media página; en cambio, si se quiere escribir el análisis que establecen los pensamientos del sueño se requiere un espacio seis, ocho o doce veces mayor. (FREUD, 1978a, p. 287).

En el lenguaje interiorizado, el fenómeno llega a su punto culminante. Una sola palabra está tan saturada de sentido que se requerirían muchas otras para explicarla en el 
lenguaje exterior. No es raro que el lenguaje egocéntrico resulte inexplicable para los demás. (VIGOTSKY, 1995, p. 124).

La equivalencia de ambas citas nos coloca en la pista de la equivalencia de los procesos. Máxime teniendo en cuenta que si comparamos las cómicas y raras creaciones léxicas de los sueños que describe Freud con aquello que se denomina Aglutinación de palabras en el fenómeno del Lenguaje Interior que Vigotsky (1995) define como la formación de neologismos sobre la base de la unión de diferentes términos en uno solo.

Dentro del esquema vigotskyano nos referimos a las características de la Endofasia o lenguaje egocéntrico que culmina en la formación del Lenguaje Interior. Así la aglutinación de palabras que hemos visto y el desplazamiento de sentido entre los distintos términos que finalmente concluirán en la construcción de la frase extendida no pueden dejar de resultarnos extremadamente similares a los procesos de condensación y desplazamiento (VIGOTSKY, 1995). El mismo Freud (1972) destaca que tanto el proceso estas cualidades del Funcionamiento del Inconsciente se observan con mayor precisión y frecuencia en las producciones verbales, tanto del sueńo como en los actos fallidos y en el chiste.

Resultando de ello también el corrimiento de sentidos. Efectos estos que se encuentran en la base de toda producción metafórica.

Si bien en la descripción del fenómeno del desplazamiento Freud hace hincapié en la transmutación del acento psíquico de ciertos recuerdos, esto sólo puede producirse en virtud de la capacidad de transferir catexias (permítaseme conservar el término original de Freud, a pesar de sus reminiscencias bioenergéticas) entre representaciones diversas. Es decir, sólo con el deslizamiento del sentido subjetivo entre dos elementos de un pensamiento (que, como bien describe Vigotsky, sólo puede dividirse en función del lenguaje) se logra el efecto descripto.

Realmente, no hay que realizar una muy ardua labor intelectual para encontrar la conexión de esto con el concepto de influjo de sentido.

Pero no se detienen allí las características descubiertas por Vigotsky en el lenguaje egocéntrico. La preeminencia, preponderancia, del sentido sobre el significado es una de sus características centrales. Hemos desarrollado en el libro y en distintos artículos, que dicha peculiaridad se asocia indisolublemente a la 
que Freud describe bajo el nombre de principio del placer. Concepto este que generó una innumerable cantidad de debates, rechazos y fuertes discusiones. Muchas de esas debido a una errónea comprensión. Aunque también, justo es decirlo, debidas a las propias carencias del concepto psicoanalítico. El mismo Vigotsky realiza críticas a la presunción del imperio del principio del placer sobre el de realidad. No obstante, en todas las obras en que aparecen estas críticas, a escasos párrafos de la misma Vigotsky da ejemplos de cómo el niño antepone sus deseos a la aceptación de un fracaso en la realidad.

Vemos pues que las producciones psíquicas hasta aquí descriptas, contienen ciertas particularidades a partir de las cuales podemos deducir que el encuentro entre las características propias que se adquieren a través de los instrumentos de mediación semiótica deben atravesar dramáticas derivaciones gracias a las cuales las peculiaridades del pensamiento preconceptual, se van adaptando paulatinamente a las nuevas imposiciones y requisitos que supone la interiorización del manejo de los instrumentos del pensamiento. Dicho pensamiento preconceptual tiene, al decir de Vigotsky (1995), característica que son propias de un pensamiento basado en las leyes de la perceptualidad. Es decir que el orden sincrético y perceptual impera sobre el orden de la abstracción y la discriminación, inherentes al pensamiento racional. El pensamiento así se convierte metafórico y metonímico: instancia de la letra lacaniana. A un lector avisado no se le escapará que existe también un antecedente que ha conectado las cualidades del Proceso Primario con dos principalísimos tropos lingüísticos: La Metáfora y la Metonimia. Román Jakobson en un estudio sobre la afasia, conectó esos tropos con las cualidades del funcionamiento Inconsciente. Esto sirvió de inspiración para que Lacan (1984) en su artículo La Instancia de la Letra en el Inconsciente o la razón desde Freud lanzara su provocativa formula en la que afirma que "es toda la estructura del lenguaje lo que la experiencia psicoanalítica descubre en el Inconsciente" (LACAN, 1984, p. 489).

Retomando el hilo del desarrollo del Lenguaje interior vemos que dicha circunstancia coincide con la evolución hacia el pensamiento conceptual descripta en las investigaciones de Vigotsky realizadas a través de la modificación del método de indagación de Asch-Rimat realizado por el propio psicólogo ruso y un discípulo fallecido muy tempranamente: Sechenov. A partir del cual Vigotsky descubre y describe cómo desde una lógica egocéntrica, sincrética, productora de coagulaciones subjetivas de orden perceptual en las diversas clasificaciones, se van adquiriendo progresivamente las capacidades del manejo 
de los instrumentos del pensamiento que permiten un nivel de discernimiento lógico que desemboca en las clasificaciones de orden conceptual. Podríamos decir que progresivamente el pensamiento va desde un orden metafórico subjetivo a un orden abstracto objetivo.

El propio Vigotsky (1995) nos alerta -tanto en la evolución del lenguaje interior como en el progreso del pensamiento conceptual- que dichos procesos no cumplen, en todas las dinámicas psíquicas, un desarrollo lineal ni tampoco que se apropien de todo el funcionamiento psíquico. Dice Vigotsky que junto a estas producciones conceptuales coexisten producciones psíquicas de otro orden.

Como vemos existe una dramática adecuación de un pensamiento de orden perceptual y subjetivo a otro de orden conceptual y objetivo. No debemos engañarnos este último orden no impera en todos los procesos psíquicos. Existen zonas en las que la subjetividad se rebela y se revela a través de producciones que dan lugar a un nuevo tipo de interpretaciones.

\section{El arte del saber}

Pero existe un campo de producción intelectual en el que el pensamiento subjetivo se encuentra con los instrumentos del pensamiento conceptual sin tener que adaptarse rígidamente a las imposiciones de dichas herramientas. Las producciones artísticas, pues de ellas estamos hablando, han servido casi desde los albores de la existencia de la humanidad como el medio privilegiado a partir del cual las subjetividades logran expresarse a través de los instrumentos semióticos sin ceder completamente las peculiaridades del sentido personal a las estrictas condiciones del significado. El arte es el campo privilegiado de la metáfora, del sentido personal, o al decir de Vigotsky (1972) el instrumento social del sentimiento. Esto es, la herramienta que inventó la sociedad para dar expresión a las construcciones subjetivas que no tienen lugar a través de las estructuras conceptuales consagradas.

Tal como nos han enseñado varios estudiosos de las distintas disciplinas del arte (ECO, 1992; JAKOBSON, 1985), éste, a partir de la modernidad, recombina los elementos perceptuales de los que está compuesto de forma tal que su cierre y su interpretación solamente pueda constituirse en el espacio de intercambio que se establece entre el autor y el receptor. Por lo que la estructura perceptual queda absolutamente privilegiada por sobre la conceptual. 
Román Jakobson hizo un muy profundo análisis de la relación entre la poética y la linguística. Jakobson (1985, p. 178) escribe acerca de la función poética "La función poética proyecta el principio de la equivalencia del eje de la selección sobre el eje de la combinación". Es decir que el poeta escoge las palabras, de entre las posibles, en función de sus cualidades de similitud o diferencia (básicamente de orden perceptual) en detrimento del principio lógico de la contigüidad. También Paul Valery dirá en un famoso apotegma que la poesía es "un dudar entre el significado y el sonido". Sigue Jakobson (1985, p. 189, subrayado mío):

En poesía no sólo la secuencia fonológica, sino asimismo cualquier secuencia de una unidad semántica tienden a formar una ecuación. La similaridad sobrepuesta a la contigüidad confiere a la poesía su esencia enteramente simbólica, múltiple, polisemántica [...]. Dicho en términos más técnicos, todo elemento secuencial es símil. En poesía, en la que la similaridad se sobrepone a la contigüidad, cualquier metonimia es ligeramente metafórica y toda metáfora tiene una tonalidad metonímica.

La ambiguedad es carácter intrínseco, inalienable de todo mensaje centrado en si mismo [...]. La primacía de la función poética sobre la función referencial no elimina la referencia, pero la hace ambigua [...]. En la lengua referencial, la conexión entre el signans y el signatum se basa totalmente en su contigüidad codificada, llamada, con frecuencia (hasta llegar a la confusión), "arbitrariedad del signo verbal”. La importancia del nexo sonidosignificado es un simple corolario de la superposición de la similaridad sobre la contigüidad. El simbolismo acústico es una relación innegablemente objetiva que se basa en una conexión fenoménica entre varios modos de sensibilidad diferentes, sobre todo entre la sensación visual y la acústica.

Como vemos Jakobson (1985) hace descansar este corrimiento del lenguaje desde la preeminencia del significado que impera en lo que él da en llamar lenguaje referencial, que no sería otro que el lenguaje coloquial y científico, hasta la preeminencia de la ambigüedad del lenguaje poético, en 
una radical modificación de la estructura del lenguaje que rompe la ecuación saussureana de Significante/significado, haciendo que este último se deslice en la cadena significante realzando su cualidad de sentido. Todo ello en función del establecimiento de pautas de conformación del discurso dando preponderancia a aspectos de orden perceptual o sensible.

Es de hacer notar que aquello que Jakobson (1985) nos señala, acerca de la ruptura de la "arbitrariedad del signo" que es reemplazada por una lógica sensorial diferente, refuerza la gran propuesta de Jean Paul Bronckart (2002, 2003) quién expresa que, desde el plano lingüístico, la conciencia descansa sobre dicha arbitrariedad. Es decir, allí donde se quiebra la ligazón personal que puede establecerse entre la imagen-significante y su significado. La conciencia por tanto descansa sobre la ruptura de ligazones naturales, reemplazadas por otras construidas socialmente.

Rota pues la relación arbitraria, vemos que esto da lugar a un interjuego sensorial que desfavorece la guía consciente del proceso de comprensión y da lugar a la posibilidad de resolver desde el sentido personal y aún desde el inconsciente la relación entre el texto y su sentido. Lo cual no significa que el Sentido Personal sea inconsciente por sí, pero su permanencia en la conciencia cuando colisiona con el significado que debiera representarlo (que como ya señalara Leontiev (1978), no siempre lo hace y, diríamos nosotros, en ciertos aspectos lisa y llanamente lo contradice) es altamente efímera o inexistente.

Por su parte Umberto Eco (1992) en Obra Abierta tras un pormenorizado análisis y una recopilación de gran parte de la producción académica acerca de la creación artística, va demostrando que el meollo de la misma se constituyó en el crecimiento de la ambigüedad del mensaje transmitido, hasta llegar a la obra de arte actual, en la que el mensaje debe ser tan indeterminado como sea posible para que dé lugar al cierre del sentido por el lector. Escribe Eco (1992, p. 94): "Ante todo vemos de qué manera el arte de todos los tiempos parece algo así como una provocación de experiencias voluntariamente incompletas, súbitamente interrumpidas a fin de suscitar, gracias a una "expectativa frustrada", nuestra tendencia natural a la terminación".

Aunque no acordemos con la concepción Gestaltica en la que se basa esta hipótesis de Eco, queda claro en esta cita que lo que el arte ofrece al espectador es un instrumento de pensamiento no cerrado en si mismo que invita al mismo a cerrarlo partiendo de su propio acervo subjetivo. 
Así el lenguaje poético como tan agudamente lo describe Jakobson (1985), retrotrae al significante a su relación primordial con el pensamiento: la de ser estímulo perceptual. Reinstala al pensamiento perceptual en el centro de la escena. Ya no sanciona negativamente al vínculo individual con lo percibido, sino que lo estimula, lo acicatea, pero no le permite tampoco salirse de las márgenes del vínculo arbitrario. El lenguaje poético navega en las ambiguas aguas que dividen al significado, al que aporta la variabilidad individual (como las especies biológicas a la variabilidad de información genética) y el sentido al que permite deambular con mayor libertad pero siempre asido a las amarras de la comunicabilidad, del "bien común", de la palabra como partera del pensar y medio de transmisión. Pero principalmente como atadura social, reguladora por excelencia del pensar que lleva a la acción.

Como podemos ver entonces es a partir de un medio como el arte que el pensamiento idiosincrático logra expresarse. Evita sucumbir plenamente a las imposiciones lisas y llanas de la homogeneización del significado.

Sin embargo, Vigotsky (1995, p. 93, subrayado mío) nos advierte que el lenguaje en sus inicios, antes de lograr afianzar sus más sólidos contenidos conceptuales, participa también de las cualidades del arte: "La palabra primaria no es un símbolo estrictamente adecuado a un concepto sino más bien una imagen, una figura, un esbozo mental de un concepto, un corto relato sobre ella - aún más una pequeña obra de arte".

Dentro de este esquema conceptual podemos ver que actualmente varias investigaciones han demostrado que la introducción del arte en la currícula escolar permite mejorar el rendimiento de los estudiantes (MILLER, 1996, 2000; LIMA; LOPEZ; RODRIGO, 2004; BENITES; FICHNER, 2004). Pero esta introducción del arte se debe dar en función de ciertas peculiaridades. No debe ser una enseñanza preceptiva de las distintas ramas del quehacer artístico. Por el contrario, dicha enseñanza debe fomentar la interpretación personal alimentando así el desarrollo de un punto de vista por parte de cada estudiante. Esta condición es la que permite "elastizar" el pensamiento. Permitiendo generar así nuevas estrategias individuales de apropiación del contenido. Estas nuevas estrategias serán las que permitirán establecer un vínculo ajeno a la dominación, ya que el educando se servirá de sus propias estrategias para incorporar aquellos conocimientos que le brinda el sistema educativo.

Se logra así restablecer una estrategia de apropiación que evita el sentimiento de amenidad que produce la errónea transmisión del conocimiento 
científico a través de métodos unívocos que buscan reproducir la precisión del contenido que trasmiten. En ellas el sujeto debe adaptarse pasivamente a las estrategias que le son propuestas.

El arte así se convierte en la herramienta privilegiada que permite resolver varios de los obstáculos que se interponen en la imprescindible transmisión de conocimientos.

Si bien ya habíamos comenzado a descubrir el invalorable apoyo que nos puede brindar el arte en la educación ahora y gracias a la psicología sociohistórica podemos conocer los íntimos mecanismos a partir de los cuales esto es posible.

El marxismo como superador de la ideología individualista debe propender a la generación de individuos creativos, apropiadores críticos del bagaje histórico y social, que rompa con el encapsulamiento individualista de la producción intelectual. Sujetos a la vez que cooperativos, productores de innovaciones intelectuales, democratizando así no sólo el acceso al saber, sino también la producción intelectual. Y en este objetivo el arte puede ser una herramienta invalorable.

\section{REFERENCIAS}

BENITES, María; FICHNER, Bernd. El arte como zona de desarrollo próximo para un nuevo tipo de aprendizaje. Revista Cultura y Educación, Salamanca, v. 16, p. 155-163, 2004.

BRONCKART, Jean P. Les processus de socialisation. Le déterminisme culturel et son dépassement. In: CONFERENCIA DE PESQUISA SOCIOCULTURAL, 3., 2002, Campinas. Anais... Campinas, SP: UNICAMP, 2002.

BRONCKART, Jean P. L'analyse du signe et le genèse de la pensée consciente. Cahiers de l'Herne: Saussure, Ginebra, p. 94-107, 2003

ECO, Umberto. Obra Abierta. Barcelona: Planeta-Agostini, 1992.

FREUD, Sigmund. La interpretación de los Sueños. In: FREUD, Sigmund. Obras completas. Buenos Aires: Amorrortu, 1978a. 4v., 5v.

FREUD, Sigmund. Trabajos sobre Metapsicología. In: FREUD, Sigmund. Obras completas. Buenos Aires: Amorrortu, 1978b. 14v. 
JAKOBSON, Román. Linguística y Poética. In: JAKOBSON, Román. Ensayos de lingüistica general. Barcelona: Planeta Agostini, 1985.

LACAN, Jacques. La instancia de la letra en el inconsciente o la razón desde Freud. In: LACAN, Jacques. Escritos 1. México: Siglo XXI, 1984.

LAKOFF, George; JOHNSON, Mark. Metáforas de la vida cotidiana. Madrid: Cátedra, 1991.

LEONTIEV, Alexis. Actividad, Conciencia y Personalidad. Buenos Aires: Ciencias del Hombre, 1978.

LIMA, Marcelo G; LOPEZ, Zoe; RODRIGO, Javier. La práctica educativa entre nińos y jovenes marginados: entrevista con M. G. Lima. Revista Cultura y Educación, Madrid, v. 16, 2004.

MARX, Carlos. El Capital. México: Cartago, 1983.

MARX, Carlos; ENGELS, Federico. La Ideología Alemana. Buenos Aires: Pueblos Unidos, 1973.

MILLER, Suzanne. Vygotsky and education: the sociocultural genesis of dialogic thinking in classroom contexts for open-forum literature discussions. Buffalo, NY: State University of New York, 1996.

MILLER, Suzanne. Shaping the literacy of culturally diverse learners in literature discussion. In: INTERNATIONAL HAWAIIAN CONFERENCE ON EDUCATION. Proceedings... Waikii: University of Hawaii, 2000.

VIGOTSKY, Lev S. Psicología del Arte. Barcelona: Barral Editores, 1972.

VIGOTSKY, Lev S. Pensamiento y Lenguaje. Madrid: Visor, 1995. 2v. 
Propostas sobre Arte e Educação

\section{Resumo}

O presente texto apresenta, a partir de uma perspectiva Vigotskyana, os possíveis fundamentos das surpreendentes melhorias que se obtêm ao introduzir a livre discussão da arte no processo educativo. De como o modo metafórico de processar a informaçáo encontrase nas estratégias do pensamento individual que permitem gerar avanços na promoçáo e aquisiçáo do pensamento científico.

Palavras-chave: Aprendizagem. Arte. Metáfora.
Proposals about Art and Education

\section{Abstract}

This paper uses a Vygotskian perspective to present the possible reasons for the dramatic improvements obtained by introducing a free discussion of art in the educational process. It looks at how a metaphorical way of processing information is found in individual thinking strategies that can generate progress in the promotion and acquisition of scientific thought.

Keywords: Learning. Art. Metaphor

\footnotetext{
Alejandro H. González

E-mail: aagonzale@gmail.com
}

Recebido em: 13/3/2012

Versão final recebida em: $14 / 6 / 2012$

Aprovado em: 14/6/2012 